\title{
A Clínica Social em Situações Extremas: O Trauma na Dimensão Coletiva
}

\author{
Jamil Zugueib Neto \\ Maria Virginia Filomena Cremasco \\ Universidade Federal do Paraná
}

\begin{abstract}
RESUMO
Este artigo tem o objetivo de descrever o traumático na clínica enquanto realidade psíquica e psicopatológica, suas dimensões subjetiva e social. A realidade psíquica de um sujeito enquanto a soma de traços deixados por suas experiências relacionais, que nos dirá sobre as consequências patológicas ou não de um acontecimento potencialmente traumático: uma ruptura violenta na marcha dos eventos cotidianos e sociais. A compreensão psicanalítica do traumatismo lança luz sobre o fato de que ele não é constituído unicamente do choque provocado pelo agente exterior, mas tanto quanto pelas possibilidades de reação da pessoa que o suporta. Esse é o fundamento do tratamento psicoterápico do traumatismo. Estas aproximações de uma clínica em situações extremas partem do pressuposto de que não há uma natureza única do trauma nem das defesas mobilizadas em seu enfrentamento. O enfoque clínico do social nos mostra a importância da plasticidade cultural quando se participa com as equipes de intervenções locais e no desenho das estratégias a serem implementadas. A clínica do sujeito nos revela que mesmo que o psiquismo estenda os meios de proteção e de autoproteção para se preservar dos traumas, sua reorganização tem um custo psíquico que pode tanto favorecer quanto impedir o trabalho terapêutico.
\end{abstract}

Palavras-chave: trauma psíquico; realidade psíquica; psicopatologia; clínica social; clínica psicanalítica.

\begin{abstract}
Social Clinic in Extreme Situations: The Trauma in Collective Dimension

This article describes clinical treatment after traumatic situations, as being understood as psychic and psychopathological events with subjective and social dimensions. The subject's psychic reality represented by the sum of the traces left by his or her relational experiences tells about the consequences, pathological or otherwise, of a potentially traumatic event: a violent break in the continuity of the subject's everyday life. Psychoanalysis understands traumatism as consisting not only by the shock caused by an outside agent but as also closely related to the individual's specific ability to react. This would be the basis of the psychotherapeutic treatment of traumatism. Such clinical approaches to extreme situations are based on the supposition that there would be a single nature of neither the traumatic experiences nor the defenses mobilized to cope with them. The clinical focus of social realities shows the importance of cultural flexibility when participating in local intervention teams and designing strategies to be implemented. Clinical practice which is based on the subject shows that even if the mental apparatus is able to expand its ability to protect itself by warding off traumas, the consequent reorganization has psychic costs that can either favor or block therapeutic work.
\end{abstract}

Keywords: psychic trauma; psychic reality; psychopathology; social clinic; psychoanalytic clinical practice.

Este artigo surge das reflexões desenvolvidas pelos autores em suas pesquisas sobre o traumatismo e as possibilidades clínicas de sua superação. A complexidade do tema obriga-nos a escolha de autores que possibilite um recorte satisfatório da teoria, para que possamos atingir nosso objetivo, qual seja: a descrição teórica do traumático como realidade psíquica, e suas incidências na clínica do sujeito coletivo.

É necessário entender o termo clínico em sua etimologia que se origina de klinè em grego, o leito. A technè clinikèv (Abraham, 1961/2001) era a arte de se inclinar em direção ao doente, estar próximo ao sujei- 
to, particularizando, portanto, seu sofrimento. Entendemos então como clínica do social o estudo das relações e das disposições inter-psíquicas, tais como elas se desvelam nas estruturas e unidades sociais (atores, grupos, organizações) levando em conta suas dinâmicas coletivas próprias. Prioriza-se o indivíduo nesta interface e em situações de sofrimento, procurando compreender a sua participação nas crises ou no fracasso do laço social. É desde aí que irão se escolher as possibilidades de tratamento, considerando a sua dupla polaridade relacional (individual-grupal) a que está assujeitado.

Para tanto apresentaremos, ainda que de forma preliminar, por intermédio de vinhetas ilustrativas, dispositivos teóricos e práticos de focalização terapêutica para vítimas de traumatismos. Pretendemos assim construir um discurso (logos) sobre o sofrimento (pathos) psíquico (psiche) na forma em que ele se apresenta clinicamente no que poderíamos denominar "psicopatologia" da clínica social em situações extremas.

Compreendemos que não há uma natureza única do trauma psíquico e tampouco seus efeitos são lineares, sendo mais acertado encará-lo como a resultante da superposição de fatores ou de traumas múltiplos e de ressonância incerta e variada. Este enfoque requer auxílio de outros olhares, como já assinalava Devereux (1972) e sua proposta de uma aproximação complementar, na qual a compreensão advém de diferentes olhares sobre um mesmo fenômeno. A compreensão psicanalítica do traumatismo lança luz sobre o fato de que ele não é constituído unicamente do choque provocado pelo agente exterior, mas tanto quanto pelas possibilidades de reação da pessoa que o suporta. Esse é o fundamento do tratamento psicoterápico do traumatismo (Hanus, 2006, p. 188).

Os trabalhos que se desenvolveram a partir de Ferenczi (1932/1982) que já assinalava a necessidade de se corrigir a teoria segundo o curso de novas descobertas fornecidas pela prática, respondem a este apelo. Faremos uma breve incursão nesse processo, complexo e multifatorial, no qual as referências teóricas se constroem efetivamente sobre abordagens pluridisciplinares, mas fazendo da psicanálise o seu fio condutor.

\section{MÉTODO}

Para nos aproximar do que denominamos sofrimento psíquico (pathos) na clínica de situações extremas, sublinhamos de início a complexidade da pesquisa em psicopatologia que, segundo Wolf-Fédida (2008, pp. 54-55) consiste no manejo de variáveis que não são ainda suficientemente exploradas, e nas quais a dúvida é o meio mais operacional. Todo interesse repousa sobre esta flutuação, mas que em nada impede a pesquisa. Pierre Fédida bem assinalou que se trata de reenquadrar a cada pesquisa, o sofrimento humano, naquilo que entendemos por "sintoma", "psíquico"e "cura".

O modelo de pesquisa em psicopatologia e na clínica do social se concebe como uma pesquisa aplicada, que leva em conta a pesquisa direta (ou pesquisa ação) na dinâmica dos processos em curso junto aos atores. Um modelo que permite uma representação não estável inclui no seu curso a possibilidade de alteração, pois a vida psíquica é uma organização singular do indivíduo que se tece na diacronia de seu processo de subjetivação e que tem início em sua família. Portanto fatores como temporalidade e movimento no seu percurso não devem ser esquecidos. "O sintoma contém a história através da qual o indivíduo procura seu lugar e sua identidade" (Wolf-Fédida, 2008, p. 55). É nesse sentido que nos referimos à clínica em sua dimensão social. Apresentamos a seguir uma elaboração não exaustiva de sistematizações teóricas desta clínica do trauma e sua reintegração pelo sujeito. Ferenczi é autor incontornável para se compreender a evolução da pesquisa psicanalítica na abordagem dos sentimentos dolorosos ligados aos traumas, às carências relacionais e aos fracassos da empatia.

Seguindo a metodologia anunciada, serão apresentados elementos da observação clínica por intermédio de vinhetas que objetivam ilustrar situações que, resistindo à representação teórica tradicional, levaram os pesquisadores a engendrar o caminho aqui percorrido. Descrevemos materiais recolhidos de entrevistas e situações clínicas de pesquisas anteriores (Cremasco, 2008; Zugueib Neto, 2005), para nossas reflexões sobre o sujeito em face de situações paroxísticas. As análises partem de exemplos do Líbano, país que conhece conflitos desde antes de sua fundação como estado-nação, e que na continuidade de conflitos de sua história, atravessou uma guerra político-confessional interna entre 1975-1991. Pouco depois quando o país conhecia seus primeiros passos na recomposição de sua infraestrutura, foi novamente semidestruído por bombardeios de Israel em 2006. Por fim é realizada uma discussão na qual expomos a reciprocidade entre a teoria e sua aplicação.

\section{Sobre a Clínica do Social}

Antes de tudo sublinhemos com (Barus-Michel, Ridel, \& Giust-Desprairies, 1996) que a dimensão social é o local onde os indivíduos tecem seus relacionamentos como companheiros, aliados, referência 
(Freud) e oposição. O social é construção estruturante, no que se compartilha e se reconhece de comum entre indivíduos pertencentes a uma unidade social. Esta referência abre aos membros a possibilidade de sentirem-se um "nós", permitindo neste laço a criação de um imaginário compartilhado de orientação e de adaptação entre si e o meio. Estas interações estabelecem os códigos sociais e as leis que irão forjar a assunção unitária, articulando os elementos dispersos em conexões de sentido e hierarquias de significações coletivas. Dessas relações intersubjetivas, vão se desenvolver os processos identitários dos sujeitos reunidos sob os mesmos signos, que por sua vez vão carregar no seu corpo, as marcas de seus traços distintivos. Em situações de ameaça e de incerteza, os apelos aos próprios recursos individuais se conectam à história de sua comunidade, na procura de um sentido.

Pode-se notar algo diferente nos mecanismos individuais e nas ações coletivas em experiências de desastres naturais e de conflitos armados. A memória social e os mitos fundadores, como vetor de referência e apoio, terão pesos diferentes nessas situações. Nesta última os eventos paroxísticos são urdidos, ao longo da história de atritos de uma comunidade. Os sofrimentos e as humilhações que marcam o seu trajeto irão propiciar a perduração do ressentimento. Afeto que não será preponderante nos desastres naturais, onde o evento inesperado de destruição vai provocar a tendência de um movimento de solidariedade social. $\mathrm{O}$ estupor e a desorientação provocados pelo evento inesperado contrapõem-se à necessidade urgente de uma resposta eficaz de reorganização e de controle emocional.

Nos conflitos étnicos (as referências para nossos exemplos), suas causas não buscam objetivos financeiros ou invasão de terras, o ódio é animado contra um povo ou uma cultura diferente. Como não existem fronteiras definidas, o campo dos conflitos provoca a divisão dos indivíduos em retalhos geográficos incertos, os vetores centrífugos de união e fortalecimento das fronteiras do grupo serão movidos pela urgência de defesa. A radicalização de condutas e a leitura ideológica do panorama social exacerbam a coesão, e acompanha o movimento dos confrontos bélicos e sua marcha de vinganças. Conflitos deste tipo serão os mais mortíferos, o inimigo passa a ser um conjunto, compacto e indiferenciado.

Como trabalhadores da saúde mental cabe uma questão que atravessa a clínica social e a ética: que significado e o que pode encobrir os termos restabelecer, curar, reparar, esquecer, perdoar, quando se traba- lha em situações deste tipo? Lembramos o que foi discutido por Miriam Cabra (2005): "restabelecer" um sujeito afetado é insuficiente para livrá-lo do sentimento de humilhação, da vergonha e do ressentimento.

Nossa intervenção vai então enfatizar a dimensão simbólica singularizada dos eventos traumatizantes, enquanto significação psicológica, moral, política e religiosa que os sintomas sinalizam.

O sentimento de segurança, proteção e de orientação que todo indivíduo necessita, é instalado concomitantemente ao processo de identificação ao seu grupo de pertencimento. Como vimos, construído nas interações subjetivas com seus pares e ancoradas nos seus processos históricos. Estes vão condicionar as práticas, as alianças e as representações significativas de uma ideologia compartilhada. As instituições moldadas neste processo, regulam, sustentam e direcionam seus elementos nas situações de urgência.

Portanto, a escuta junto aos atores, modulada nestes fatores vai nos fornecer as chaves do campo a intervir e possibilitar a detecção de seus potenciais elementos de superação tanto individuais como coletivos, assim como de seus aspectos mais enfraquecidos. É esta atenção que vai possibilitar a emissão da narrativa do sujeito afetado e com ela o enredo grupal. Esta perspectiva oferece as estratégias de se suplantar o modelo médico do DSM-IV, pois o Distúrbio de Stress Pós-Traumático universaliza na sua classificação o sintoma, rotula e impede a compreensão do sofrimento singularizado.

Enfim com quem iremos trabalhar? Com vítimas, afetados ou doentes? E no caso de conflito armado, com carrascos e perpetradores de assassinatos em massa? O olhar diferenciado sobre esses sujeitos vai implicar novas compreensões do sofrimento humano, que por sua vez vai instigar estratégias diferenciadas da intervenção. Quanto ao alcance destas, não podemos esquecer nossas limitações, como também saber diferenciar no final deste processo, que os fenômenos e sofrimentos traumáticos associados a acidentes naturais, materiais, morais, afetivos ou ainda a motivações políticas envolvidas em confrontos armados, não se dissipam completamente na interpretação clínica e nem na retomada da atividade social.

Também não há porque acreditar que um indivíduo que ultrapasse uma situação de crise, fique imune ou fortalecido para outras situações traumatizantes. Cada situação tem sua significação própria e acontece em um dado momento do ciclo vital de um sujeito, no qual sua história, suas significações e desejos naquele momento, contribuem para seu fortalecimento ou, ao 
contrário, deixam-no suscetível e fragilizado para novos enfrentamentos.

Depreende-se então que são múltiplas as implicações de uma perspectiva psicanalítica-cultural para ressituar, ou singularizar o trauma. Esta posição exige atenção para as formas individuais e grupais de expressar a dor, de responder a um stress, e nas suas estratégias de resolução de problemas. Esta orientação vai implicar na organização de equipes multidisciplinares vinculadas aos trabalhadores e líderes locais. Os programas a serem implementados devem estar amarrados às tradições locais e no conhecimento popular, prestando atenção nas suas crenças, nos seus valores e na memória coletiva, principalmente quando os trabalhos se desenvolvem em situações de guerra.

O tratamento projetado deverá dar condições para os sujeitos da intervenção, reconstruir suas identidades e um projeto existencial reinseridos na sociedade que se tenta renovar ou recuperar. Outro aspecto a ser sublinhado como ponto de partida clínico será reconhecer que, envolvido em um movimento de massa, o sujeito deixa ao menos por um momento, suas preocupações neuróticas e se dedica às necessidades e interesses movidos pelos movimentos do grupo: "Lá onde se produziu um choque possante terminando em uma formação de massa, as neuroses recuam e podem desaparecer ao menos por um tempo" (Freud, 1921/1981b, p. 170). A crise vivida pelos atores nessas situações extremas, no que elas trazem de imprevisibilidade e de ameaça, vai exigir esforços redobrados para a manutenção de um sentimento de unidade interna e no escoamento das excitações provocadas pela irrupção do traumático. Na possibilidade da dispersão, o poder das operações psíquicas e da eficácia dos mecanismos egoicos para a manutenção de uma razoável estabilidade do eu, serão postos à prova.

\section{Considerações sobre o traumático na clínica do sujeito}

Desde o Projeto para Uma Psicologia Científica, Freud (1895/1973) afirma que o traumático não é o acontecimento real, mas a lembrança recalcada de um cenário insuportável. Da interpretação realizada após o choque, o fruto decorrente será esta representação angustiante. Nasce assim a teoria do après-coup na clinica freudiana, que aponta para uma temporalidade própria do psiquismo, inscrita em três tempos (Freud, 1924/1987): o tempo do acontecimento, um tempo de latência e um tempo no qual o acontecimento produzirá seus efeitos e sintomas, como expressões $(\log o s)$ e tentativas de resolução do conflito (pathos) em ques- tão. Podemos considerar estas representações inconscientes como "corpos de significação" que se enredam na realidade psíquica do indivíduo. Serão nós de desejos e de angústias provenientes de acontecimentos reais e de fantasmas, que irão se imiscuir na leitura da realidade material do sujeito.

Se for somente ao momento do après-coup que o acontecimento se torna traumático e produz seus efeitos, isso indica para Balestrière (2001), que não apenas o presente interpreta o passado, mas que ele também o recria, fazendo-o existir a partir desses efeitos. Reciprocamente poderíamos dizer que os efeitos do passado, determinam o presente pela transferência dos afetos pretéritos à situação atual. Assim neste jogo transferencial da temporalidade psíquica, o tempo, o espaço e a causalidade de um evento, não conhecem linearidade.

Mas cabe lembrar que nos conflitos étnicos, as marcas dos sofrimentos vividos durante os confrontos, podem se prolongar através do ressentimento mantido pela memória. A perduração da lembrança traumática mantém a relação de ódio e vai ter papel de prolongamento e de manutenção da crise pessoal. Ela recria o passado e significa o presente, podendo funcionar também como força de resistência. Mostraremos mais abaixo um recorte da entrevista com um combatente engajado nas milícias druzas durante a guerra de 1975.

A memória, vista por Freud como sendo capaz de remodelagens e modificações depreende uma concepção de elaboração na construção da realidade psíquica, ela será o próprio processo de sua simbolização. Pois no símbolo mnêmico que conjuga estes três tempos que estamos nos referindo, vem à luz através de sua representação, e com ela os efeitos do après-coup da lembrança. Este traço por sua vez, vai se inscrever na história relacional do corpo do indivíduo, alterando assim a sua construção identitária. Neste caso o ódio mal elaborado, tem seu desdobramento no ressentimento, que faz laço na memória social. Eventos passados da comunidade são assumidos pelo sujeito e significados como traço identitário, fazendo união grupal na leitura do presente.

Exemplo de Walid, comandante das milícias druzas na guerra de 1975:

Nossa história mostra que a cada vez que há um conflito no Líbano, os druzos são colocados em cena. Os eventos que vivíamos eram a repetição de nosso passado e confirmavam que a cada 50 ou cem anos, nós somos levados à frente da batalha. Isso mobilizou a organização

Interação em Psicologia, Curitiba, 2011, 15(n. especial), p. 35-45 
de nossa defesa, obrigando um rápido restabelecimento psicológico depois da morte de nosso líder. A história de sucesso de nossos antepassados, nos afrontamentos anteriores nos lembrava que estávamos imbuídos dos mesmos papéis. Não houve pânico, e um sentimento de designação do destino aumentou nossa coesão. (Zugueib Neto, 2005, p.97)

A assunção dos ícones históricos na identificação da defesa comunitária vai resgatar o passado na leitura do presente, e promover uma realidade psíquica que sustenta a desorganização pela perda do líder e pela ameaça do inimigo. Voltaremos mais adiante a este tema.

A renúncia da teoria traumática das neuroses e a descoberta de uma realidade psíquica fantasmática complicam segundo Houzel (2006, p. 253), as relações entre os acontecimentos potencialmente traumáticos e suas eventuais consequiências patológicas. Segundo o autor a fonte do trauma psíquico é, sobretudo, intrapsíquica. Ela se constitui na pulsão de morte, que no estupor, vai impossibilitar as ligações psíquicas de sentido, e a inscrição social do sujeito, impedindo a alteridade. Este fator vai fixar um modo de descarga, típico da repetição traumática (modelo do sonho em Freud, 1920/1981a). Veremos em seguida como o irrepresentável do traumático se articula à pulsão de morte. A realidade externa não pode mais ser responsabilizada como fator único traumatizante, como no primeiro modelo. Seu papel é mais o de desmentir ou de confirmar a violência desta destrutividade interna. É necessário dizer que é a realidade externa, permeada de relações, que se trata neste novo modelo. Para Houzel (2006), não é mais aquela ao qual Freud chamava de sua neurótica e que se tratava de fatos, de acontecimentos localizáveis no tempo e no espaço, inscritos num desenrolar histórico. Agora, trata-se de relações (Laplanche, 1993). É a relação da criança com o seu meio que constitui para ela, a partir de agora, a realidade. É por intermédio dela que o mundo interno será representado. A realidade psíquica será a soma de traços deixados por essas experiências relacionais, enquanto que a realidade exterior será isso que a percepção dá a conhecer do mundo ao redor. É essa a realidade psíquica de cada um, que nos dirá se um acontecimento foi ou não traumático para ele.

O estupor causado por um evento desruptor quebra, impede sua simbolização e concomitantemente advém a desorganização. Consequientemente haverá um enfraquecimento do sentido de si - mesmo e a perda dos referenciais da situação. Para Ferenczi
(1932/1982) existem choques que são equivalentes ao aniquilamento do sentimento de si, da capacidade de resistir, de agir e de pensar visando defender o si próprio. Pode ser também que nestas condições extremas os órgãos que asseguram a preservação do eu, abandonem ou ao menos reduzam, suas funções ao extremo.

A palavra Erschütterung, comoção psíquica, vem de Schutt, fragmentos (de um objeto destruído, quebrado em pedaços); ela engloba desabamento, a perda de sua forma própria e a aceitação fácil e sem resistência de uma forma outorgada, à maneira de um saco de farinha (sem esperança de êxito na resistência). A comoção psíquica sobrevém sempre sem preparação e precedida do sentimento de se estar seguro de si, no qual a marcha dos acontecimentos vai revelar a impotência do sujeito. Acrescente-se a possibilidade da vergonha e da humilhação. "É como alguém perceber que superestimou sua força, e que vivia até então na louca ilusão que tal coisa não podia lhe acontecer, 'não pra mim', como nos fala Ferenczi" (1932/1982, p. 139).

Nesse momento dois tipos de reações à situação poderão advir: Elas serão inoperantes e repetitivas como expressão de um ser submergido pela desorganização ou irão se inscrever num movimento criativo e eficaz para o seu combate, seu controle e sua superação. Em ambos os casos há um preço psíquico a ser pago, como a formação de sintomas.

Nanci, 24 anos, solteira, professora, Khyam, sul do Líbano:

Eu tinha seis anos quando meu pai foi preso, lembro como ele foi levado de casa à prisão pelos invasores, foi muito humilhante. Eu era muito ligada a ele e até agora eu não posso esquecer como ele foi tratado. Depois disso minha mãe e tias foram obrigadas a abandonar nossa terra, e deslocaram-se de uma região a outra. Quando os bombardeios começavam me perguntava: quando um míssil vai nos acertar? A que horas nós vamos morrer? Fiquei seis dias isolados, chorava todo o tempo. Eu pensava somente em meus pais e que eu não os veria mais... Dos momentos mais dificeis eu não consigo me exprimir e descrever meus sentimentos. Eu vi a morte na minha frente. A cada período há uma guerra, esta guerra terminou, mas esperamos uma outra. Vivemos sempre em suspense, não conseguimos nos acalmar $e$ não há equilíbrio. Esse períodos são os períodos de perda em nossas vidas. Você sente que nada vale a pena. O ódio e a honra ferida continuam. Eu sou inquieta, instável. Às vezes eu sinto que quero me matar.

Para Ferenczi (1932/1982) o que define o trauma é a impossibilidade de adaptação à nova situação. Ela 
ultrapassa as capacidades pessoais e o indivíduo se abandona nas tentativas infrutíferas de seu controle. Os eventos de separação vividos por Nanci aos seis anos, sentidos profundamente como dolorosos e ameaçadores, se acrescentam a um presente extenuante, que abala suas capacidades pessoais de controle. A atualidade é vivida sob a tendência de renúncia onde sua capacidade psíquica sob influência da pulsão de morte funciona em comoção. Nesse caso a consciência fica fora de circuito e se desconecta da percepção, realizando um fenômeno particular no qual as percepções traumáticas não são bem percebidas, (a dificuldade de expressar confessada pela jovem) e não representáveis conscientemente. É o que Ferenczi chama de clivagem narcísica, uma parte de si que sabe de tudo, mas não sente nada e outra que sente tudo, mas não sabe de nada.

A humilhação e a vergonha decorrentes dos fracassos nos conflitos étnicos é um afeto de comando, segundo Abraham (1972), ou seja, imposto do exterior e por meios artificiais, ele produzirá uma clivagem no psiquismo. A vergonha faz par com o segredo e a divisão do eu. A culpabilidade pode ser expiada, a vergonha não pode ser senão negada ou dissimulada. Apenas a repetição cega do traumatismo parece estar carregada de certa memória face à amnésia, que toma lugar pela aniquilação da consciência (Balestrière, 2001), tornando o acontecimento como "não-acontecido", não simbolizado. Retomaremos a discussão mais abaixo.

\section{RESULTADOS}

\section{Reintegração do traumático}

Ressaltamos anteriormente que Ferenczi se interessava principalmente pelo equilíbrio entre o individuo e seu meio mutável. Para alguns autores como Bonomi (2003), Ferenczi não teve consciência de que seu ponto de vista implicava uma mudança na metapsicologia freudiana segundo a qual o princípio do prazer buscava um equilíbrio estável do aparelho psíquico (Freud, 1920/1981a). A maneira de interpretar a tendência fundamental da vida, segundo a obra de Ferenczi poderia ser resumida da seguinte forma: a libido está à procura do símbolo (Bonomi, 2003, p. 54). Ou seja, o equilíbrio se dá por intermédio do que a simbolização realiza no aparelho psíquico, possibilitando conexões de sentido que escoam a angústia, sempre sem sentido.

A função de adaptação que deve assegurar a sobrevivência do indivíduo após a perda do equilíbrio, é assumida pelos símbolos que ligam a satisfação perdida à realização do desejo esperado, criando pontes entre o passado e o futuro, como no exemplo de Walid ou pela formação dos sintomas, como veremos no exemplo abaixo. Apresentamos um resumo de entrevista com um combatente na guerra do Líbano.

Khaldoun, 30 anos, milícia druza na guerra de 1975-1991:

Eu tinha dezesseis anos quando entrei na guerra. A perseguição sofrida em Beirute nos obrigou a fugir. Na barragem da cidade um dos soldados inimigos quis nos metralhar, seu colega interferiu e começaram a discutir. Aproveitamos a ocasião para escapar. Mais tarde, como chefe de pelotão, vivi muitos fatos dolorosos, $e$ muita coisa não quero relatar. Nossa natureza é indulgente e tenho uma faculdade de esquecer. O que me reforça e que saímos da guerra vencedores. Minha vida mudou e apesar de estarmos vivos eu me demando se somos felizes. As pessoas ficaram mais desconfiadas, nervosas e inseguras. A situação econômica é muito difícil, esta guerra financeira é pior que a guerra das armas. As relações sociais não são mais as mesmas. Cada um quer ficar em casa e as visitas sociais se reduziram bastante. Vivemos o cotidiano simplesmente, sem grandes emoções. No grupo de amigos falamos sobre nossos projetos, mas vejo que todos falam mais para reduzir suas ansiedades. Para que servem nossos projetos se estamos num estado de estagnação? O confessionalismo aumentou e isto afeta nossa vida, nossa comunidade sente-se ameaçada e fraca no jogo do poder. As orientações de nosso líder nos afeta também, a força dele e a nossa, são as mesmas. Ele tem a sua força da nossa, $e$ nos somos fortes porque ele o é. A comunidade nos acolhe e agradeço a Deus, por estar como estou, pois esperava o pior. Estas coisas influenciam nossa disposição e sentimos nostalgia do passado. Mas devemos nos consolar, não podemos fugir de uma ansiedade para dar lugar à outra.

Este relato de uma vida cotidiana cindida nos mostra como os símbolos permitem o ajuste ao novo meio, sem renunciar à esperança de resistir, de superação, de retorno à satisfação, em oposição ao abandono de submersão ao traumático. Para Bonomi (2003, p. 5455), nós podemos tirar algumas conclusões da ideia de que os símbolos são os mediadores entre o principio de prazer e o princípio de realidade seguindo os esquemas do pensamento de Ferenczi.

A sintonia afetiva vivida entre amigos se articula com os sentimentos de enfraquecimento vital, incitando um compartilhar destes estados. Por sua vez esta conexão vai modular o estado do eu de Khaldoun com seu grupo mais próximo. Os projetos discutidos em grupo lançam imaginariamente estes sujeitos a um 
futuro apaziguador. Mesmo conscientes das dificuldades, o lugar simbólico almejado aprofunda seus laços, obrigando a repensar e aceitar o presente estressante. A força que se potencializa na relação com o líder, e o que ele representa, terá então a função de unificação: religar o corpo ao mundo exterior; as emoções às representações; o passado ao futuro. A conexão se potencializa na comunidade, que vai ter papel de garantia na relação com o presente. "Quando uma pessoa soçobra frente a um trauma, é precisamente essa função de unificação que é quebrada" (Bonomi, 2003, p. 55). Daí nos referirmos à clivagem como mecanismo defensivo atuante.

Uma consequência típica dessa situação é descrita por Ferenczi (1932/1982) como uma ruptura entre o sentimento e o intelecto. A vida emocional estando banida de representação regressa a sensações corporais puras (pulsão de morte), dissimulando-se no inconsciente corporal. $\mathrm{O}$ intelecto distanciando-se de toda emoção, tem seu progresso sob forma de uma performance de adaptação. Mas como sobrevivência e não como reconstrução subjetiva, bem exemplificada por Khaldoun. A clivagem é, sobretudo, uma forma de sobreviver a um traumatismo, mais do que uma maneira de se reconstruir após ele.

Vale ressaltar que ao situarmos os conflitos étnicos como traumáticos não estamos generalizando essa realidade como traumática, nem fazendo nenhuma correspondência diagnóstica. A realidade psíquica do sujeito depende de sua percepção e de sua capacidade defensiva como vimos acentuando.

\section{Sobre as defesas}

Segundo Braconnier (1998) a noção de mecanismo de defesa, como tendo um papel homeostático, engloba todos os meios utilizados pelo eu para controlar e canalizar os perigos internos e externos. Entretanto, eles podem ser mais ou menos adaptados, em função do contexto de sua utilização e da rigidez de sua expressão. Sublinha o autor que a análise do funcionamento psíquico do sujeito, pode se decompor em: confrontação do trauma e resistência à desorganização psíquica, que se caracteriza pelo recurso aos mecanismos de defesa de "urgência" para se proteger da efração psíquica, como são as defesas primárias negação, repressão dos afetos, projeção, passagem ao ato, comportamento passivo-agressivo, deslocamento e fantasia; a segunda fase é a integração do traumatismo e da reparação e supõe o abandono de certas defesas de urgência para privilegiar defesas secundárias, mais flexíveis e mais adaptadas a longo termo: criatividade, humor, intelectualização, altruísmo, sublimação. O funcionamento psíquico passa por um processo chamado de "mentalização" que faz apelo aos representantes psíquicos e à simbolização dos afetos. Trata-se de se conferir um sentido à ferida. Vejamos este exemplo, que iremos comparar com Nanci.

Rabiya, 48 anos, casada, professora. Bint J'beil, sul do Líbano:

Meu comportamento e minha vida diária se organizam através de minha seita.

Na primeira época antes da guerra (1975), eu via o Líbano crescendo e progredindo, estava contente de ver que eu estava crescendo e continuando minha educação. De repente, veio a guerra, as coisas começaram a voltar para trás e os sonhos a encolher. Os inimigos ao redor de nossa cidade eram muitos, e começamos a migrar em nosso próprio país. Era uma fase sem equilíbrio e sentíamo-nos em crise, onde não éramos parte do todo... como se fossemos isolados dos outros. Eu via uma guerra doutrinal ridícula, onde não sabíamos por que lutávamos. Houve momentos de vergonha e humilhação, e jamais esqueço quando me pararam numa barragem no bairro de Achrafieh, eu tinha 10 anos, $e$ fui ameaçada de morte.

Com os combates vitoriosos sobre Israel durante a sua ocupação no país, o sentimento da derrota (árabe) de 1967 começou a encolher, e começamos a marcar vitórias sobre eles. A vitória maior foi a de 2000, quando eles partiram do sul. A derrota que tivemos no passado, em minha opinião não criou uma frustração eterna. A frustração é temporária, depois é ultrapassada e sempre há uma nova partida.

Mais tarde eu acompanhei o trabalho de construção de 6 andares de minha escola, e ela prometia um futuro brilhante. Veio a guerra de 2006 e destruiu toda a construção, um trabalho de 4 anos. Psicologicamente me adaptei rápido. Voltei em 15 de agosto, em 14 foi o cessar fogo, e estive presente nas ruínas da escola. Consegui não chorar, quando todo mundo ao redor, funcionários e outros choravam. Pensei que isso não deve levar a nada e reiniciamos a reconstrução, as aulas não foram interrompidas. Agora estou tranqüila, a única coisa que me preocupa é uma nova guerra, e como me adaptei a outras guerras, terei que me adaptar às outras futuras.

Pessoalmente as guerras me deixam em situação de crise, mas logo me adapto e vou em frente. Não vivi uma fase de equilíbrio social para sentir algo de novo nisso. Minha vida inteira foi repleta de guerras, não há novidades nisso. Com ou sem guerra, aprendi a não sonhar e a viver conforme as circunstâncias. Ao mesmo tempo, como vivi numa família e numa comunidade onde há muita emoção e carinho isso me ajudou muito. Conside- 
ramos a comunidade xiita uma sociedade de compaixão. E como a religião nos ensina que a vida é trabalho e esforço, isso reduz a tensão e recompensa minha tristeza.

\section{Interpretação}

Abraham sublinhava que os sofrimentos aos quais a psicanálise se volta, não são necessariamente aqueles que provocam os conflitos, mas aqueles que impedem a simbolização no campo social. Simbolizar neste nível não significa uma solução repetitiva, mas uma solução aberta e criativa (Abraham, 1961/2001, p. 75).

Se para Nanci a vivência de sofrimento se prolonga nos dias atuais, pela presença do real de sua experiência, este experienciar é sentido como perda de vida e como congelamento. A violência experimentada arrasta-se como pedaço de comoção psíquica que a deixa desorientada. Seus temores se alimentam nas conexões de sentido, que seu grupo oferece na espera de uma nova guerra. A sugestionabilidade promovida nesta convivência, aliada aos temores de novas e dramáticas separações, como já acontecidas na sua história relacional, não faz mais que tornar inquietante seu humor e a viver momentos onde a pulsão de morte faz aparição.

Com Rábia os efeitos do trauma e sua desestabilização, provocam a narrativa, e com ela seus desdobramentos de sentido que vão se refletir na sua prática. A guerra teve efeitos devastadores em seu projeto de vida, pois que destruiu suas realizações concretas de uma identidade almejada (educadora) e que sempre contrabalançou com as frustrações de um entorno precário e perturbador. A escola destruída tem correspondência interna na destruição de um objeto idealizado, reflexo de suas realizações egoicas e de significado no equilíbrio de sua realidade psíquica. A princípio ela nega, recalca seus afetos como resistência à desorganização, para num segundo momento lançar-se em estratégias mais flexíveis de aceitação e de resposta aos fatos. Viver na sua sociedade eternamente convulsionada é seguir a sua história, não mais que isso. A intelectualização como mecanismo de defesa, se por um lado participa na divisão interna, distanciando-a da emoção, ela dá espaço para a criatividade atuar na reconstrução dos investimentos libidinais e amainar os efeitos estressores, de uma concepção fatalista de novas guerras vindouras. O pragmatismo no cotidiano, necessário ao seu equilíbrio, não impede as sublimações no altruísmo de suas atividades e que auxilia barrar a expressão da pulsão de morte que poderia se presentificar como ameaças de desabamento interior. A clivagem sentida como suspensão no cotidiano encontra apaziguamento na família e na sua comunidade de compaixão.

A reconstrução psíquica de Rábia, em tais situações de repetitivos confrontos armados, é trabalho contínuo, segundo Tisseron (2007) ela não tem fim e defesas como a clivagem, jamais são totalmente suprimidas. A professora na sua determinação de viver as circunstâncias segue os preceitos de sua religião, quadro de referência que lhe dá o conforto espiritual, as orientações éticas de conduta, e não descartando a esperança.

Mas o que advém da esperança? Será que temos aí indícios de dispositivos clínicos para o tratamento dos traumatizados? Se o choque que advém ao indivíduo ao ser atingido, vai causar o dês-espero, a paralisia da esperança, Ferenczi (1932/2006) vai apresentá-la como uma espécie de adesivo que junta outros elementos, que se tornaram dissolvidos pelo choque. Mesmo nos traumatismos violentos, fragmentos de uma possibilidade positiva subsistem e são enviados para o futuro, produzindo imagens oníricas e fantasmas de felicidade. Como escape de um contexto tedioso Khaldoun e seus amigos constroem mundos alternativos; para Rabia é motor na reconstrução do projeto existencial. Nanci está paralisada, seu caminho futuro é sentido como bloqueado. A recuperação desses fragmentos de esperança evidentemente não poderá faltar, se queremos intervir na reintegração psicossocial. Sem ela não há como achar o ponto de partida na escolha de estratégias de tratamentos ${ }^{1}$. De nossas observações desenvolvidas acima, depreende-se que olhamos com muito cuidado a relação medicalização e a patologização de um quadro apresentado e que pode des-subjetivar o sofrimento humano. Pois sempre ele irá se apresentar divergente, enigmático e único, portanto não fugindo da compreensão que a psicanálise sempre advogou. E isto não contradiz a procura de suportes sociais que possam auxiliar o sujeito afetado. Lembramos que no grupo de pertencimento, os indivíduos encontram uma acolhida de estabilidade e de afeto que promove enquanto mediador, relações apaziguadoras nos acontecimentos mais críticos. Estes funcionam como filtros que metabolizam o meio exterior, promovendo uma atmosfera de suporte nas trocas da experiência vivida, abrindo o caminho para as suas elaborações.

Quanto às pretensões de cura, não podemos ter a certeza de que nossas estratégias por mais holísticas ou multi-referenciais que elas sejam, possam recupe- 
rar, curar ou adequar o afetado, pois além da variedade de constituições individuais que nos deparamos, existem evidências em pesquisas com traumatizados de guerra, de possíveis cronicidades, nas quais as marcas do trauma se repercutem na transmissão intergeracional (Hanus, 2006, p. 203; Kaës \& Faimberg, 2003).

Do ponto de visto psicológico, não podemos estar seguros de que uma nova situação estressante não venha fazer irrupção novamente. Concordamos com Tisseron (2007, p. 80) para quem, acreditar numa reparação total encobre a complexidade do mundo e, notadamente pode nos fazer esquecer que ela existe.

\section{Um recorte final para as nossas derradeiras discussões}

Para dar continuidade a nossa explanação sobre os fatores que participam na significação do trauma e sua relação com o sujeito, partimos das observações de Barus-Michel, Giust-Desprairies e Ridel (1996) e Giust-Desprairies (2005) para desenvolver nossos argumentos de uma clínica social do sujeito. Os exemplos escolhidos confirmam o que as autoras sublinham, de que uma crise aparece como uma experiência terrificante, como um ataque aos referentes centrais que estruturam o ator, afetando, portanto, sua unificação simbólica. A solicitação externa invoca a representação de si mesmo, que permanece como referente subjacente. Nestes momentos a fé em si é estremecida ou reavivada (e transforma-se em esperança). Sempre então a intervenção na reorganização subjetiva de um afetado, terá como objetivo o resgate de um sentimento de coerência, mesmo ilusório, de uma identidade que se encontra abalada. Manco, razoavelmente incólume ou com marcas inapagáveis dos eventos terrificantes, é com um sentimento mínimo de apreciação de si, que um sujeito poderá recomeçar, apesar de sua afetação. Que pulsões têm preponderância na sua dinâmica atual, ou quais as que se pode resgatar no momento de nosso trabalho? Como suas representações podem se engatar nas significações sócio-culturais e com elas facilitar a busca de apoio de sua entourage mais próxima? Estas questões devem guiar nossas estratégias de ação.

Pegamos este fio para nos centrar exatamente nos dinamismos simbólicos e representacionais do sujeito, que se moldam no encontro das lógicas sociais com os dinamismos do inconsciente. A situação crítica e provocadora da dissociação do indivíduo vai provocar na sua ultrapassagem, a emergência de novos significantes na sua cadeia simbólica. Por sua vez suas represen- tações vão se associar nesta nova construção, alterando sua realidade psíquica. Se considerarmos ainda, que este processo pode ter conseqüências incertas, é porque vemos aí a possibilidade de uma crispação de afetos que imobiliza o sujeito ou abre-se a oportunidade de uma recomposição, considerando-se que esse afrontamento nunca é sem preço psíquico.

Salam, 21 anos, solteiro, estudante, Khyam sul do Líbano:

Durante a guerra (2006) nos sentíamos em ameaça contínua, assim que começavam os bombardeios pensávamos que nossa vez estava chegando. Em certo momento minha mãe sofreu um colapso nervoso e me assustei muito. O pior momento foi deixar meu pai, e partir de Khyam. Meu avô, um senhor de idade, recusou-se a sair de sua terra, e por isso meu pai teve que ficar. São marcas que não se esquecem.

A lembrança mais triste foi a destruição do edifício dos meus pais e tios, de cinco andares. Apesar do sentimento de honra depois da vitória sobre o inimigo israelense, há um sentimento de dor por perder coisas queridas, minha casa, minhas lembranças e pertences. A perda é mais psicológica do que material. Se meus filhos me perguntarem um dia sobre como era minha vida ou minha casa não tenho nenhum registro disso.

A guerra causa muitas mudanças dentro de cada pessoa. Eu por exemplo tenho uma obsessão de que a guerra voltará, e de que não iremos viver em paz jamais, a história demonstra isso.

Como a guerra me afetou pessoalmente? Por ter minha casa destruída, e com ela minhas lembranças, minhas fotos, meus livros, minhas coisas. Tenho uma grande tristeza por isso... Parecem detalhes insignificantes, mas na verdade constituem partes da minha vida. Tenho muitas lembranças, mas as mais evidentes são da época da ocupação, onde nos sentíamos deprimidos e angustiados.

A minha situação psicológica muda de um dia para outro. Às vezes estou pessimista outras vezes sou otimista. Mas tenho uma visão mais pessimista da vida... As minhas lembranças ocupam um grande lugar na minha vida.

Desde o momento em que eu nasci, o Líbano esteve em guerra: Luta interna ou guerra contra Israel. Nenhum libanês vive em um estado de equilíbrio emocional... As pressões que sofremos são de ordem financeira, psicológica, social ou política. A situação no Líbano é muito difícil, a vida é dura, a situação econômica é péssima... Nunca há segurança total, principalmente agora com esses atentados contínuos... mas têm muitas coisas que nos dão apoio e auxiliam a resistir a essa situação: as amizades, a afiliação política... isso traz um pouco de tranqüilidade psicológica. Conversamos, jogamos baratho, fumamos nargilé. 
Os passos futuros meus? Assim que terminar e conseguir uma oportunidade de trabalho no exterior, viajarei sem hesitação e sem pensar. Talvez chegue um dia em que não lembrarei que existe um país no mapa que se chama Líbano... Mas se achar um trabalho dentro do Líbano claro que lhe darei a prioridade. Viver dentro do próprio país é muito melhor do que se fixar fora...

No Líbano você deve ter esperança para poder sobreviver. Sem esperança, sem sonhos e sem ambição não tem como sobreviver nesse país e nem enfrentar as dificuldades. Tem-se que acreditar que o futuro será melhor.

\section{COMENTÁRIOS}

O Líbano é um país de guerras de memória, onde se alimenta a cultura da violência provocada pelo radicalismo etno-confessional. Os excessos sempre estiveram presentes na sua história desde os tempos bíblicos, e por estas páginas ainda se continua a matar. A lembrança recente da dor inassimilada ou das perdas irrecuperáveis se acrescentam à memória social de cada comunidade, alimentando a cadeia dos ressentimentos. Surgem desde aí várias conexões de sentido, e que para nós, interessa sublinhar, vai fortalecer as construções discursivas comunitárias que por sua vez oferece os significantes que participam no recalque, na clivagem, na resistência psíquica e logicamente na reprodução da violência.

Um dos pontos que chama a atenção no depoimento deste jovem, e que se repete em outros depoimentos, é a afirmação de que ele tem muitas lembranças. Significa um imaginário prenhe de representações de eventos marcantes e que fazem cadeia traumática na formulação de uma compreensão histórica de seu país. Esta representação, que provoca a procura de um sentido existencial para si, comporta capítulos paradoxais, feridas que ele talvez um dia "esqueça", numa fuga pro "exterior". É fuga dos excessos dificeis de assimilar e que precipita um projeto que se dissocia de seus traços anteriores. A ambivalência entre ficar (continuar os passos de sua cadeia) ou partir (romper o encadeamento) é uma das faces de seu mal-estar cotidiano.

Citaremos como reforço de nossos argumentos, as pesquisas de Badoura (1990) que listam os fatores que contribuíram à resistência do libanês, durante os anos do conflito armado em 1975. O conceito árabe de fatalismo com respeito à morte; maior tolerância na cultura com relação à expressão das emoções; aceitação da guerra como fazendo parte de sua história; a solidez da estrutura familiar e a valorização do com- batente, considerado o defensor da honra tribal e de seus princípios religiosos.

Esses exemplos adicionam-se à linha de nossa argumentação sobre as significações culturais que participam nas identificações dos componentes de uma sociedade e que servem como vetores de resistência. A espera sempre presente de um novo confronto armado, apesar da inquietação, tem efeitos mitigadores aos impactos sofridos, pelo espaço simbólico que a eles é reservado.

Outros jovens citam a renovação de suas identidades. Renovação e desencantamento com guerra ocorrem juntamente com suas atividades institucionais (todos os entrevistados são engajados). O enquadre oferecido pelos projetos comuns contribuem para o recalque e a canalização libidinal a novos objetos. Serão vislumbres imaginários que enfeixam os significantes dispersos e que se projetam a um novo lugar.

Uma reflexão clínica mais cautelosa alerta-nos que as atividades da vida diária, podem estar mascarando significações traumáticas mais profundas. Estes núcleos podem aflorar subitamente como sintomas agudos, ou acionar comportamentos em formações reativas que podem oscilar entre a depressão e a mania. Os exemplos mostram esta tendência. As atividades cotidianas funcionariam como um tampão, que impediria o retorno do recalcado, ou manteria a clivagem das experiências que necessitam simbolização. $\mathrm{O}$ fato da possibilidade de haver uma irrupção retardada faz com que se tenha cautela quanto a afirmações de suas condições psíquicas para o futuro.

A clínica deve questionar sempre o observador, incitando-o a refocalizar seu objeto de estudo cada vez que novos impasses se apresentam, tanto na compreensão quanto no tratamento do sofrimento humano. Esse dinamismo possibilita sempre um avanço para as teorias psicopatológicas e seu campo de aplicação. Nossos exemplos procuram provocar a reflexão sobre as mais diversas estratégias de tratamento, pois elas clamam pela redefinição de um campo, no qual os modelos teórico-práticos elaborados distintamente podem ser colocados em situação de confrontação crítica.

\section{REFERÊNCIAS}

Abraham, N. (1972). Pour introduire 'l'instinct filial'. Em I. Hermann (Org.), L'Instinct filial (pp. 8-58). Paris: Denoël.

Abraham, N. (2001). Le sens du symbole comme au-delà du phénomène. Em N. Abraham \& M. Torok (Orgs.) L'ècorce et 
le noyau (pp. 26-76). Paris: Champs Flammarion. (Original publicado em 1961)

Baddoura, C. (1990). Santé mentale et guerre libanaise. Bulletin de l'Académie Nationale de Médecine, n. 4, 583-593.

Balestrière, L. (2001). Causalité psychique et traumatisme. Cahiers de Psychologie Clinique, 16, 39-47.

Barus-Michel, J., Giust-Desprairies F., \& Ridel L. (1996). Crises. Paris. Desclée de Brouwer.

Bonomi, C. (2003). Trauma et la fonction symbolique de la psiché. Le Coq-Héron, 174, 50-56.

Braconnier, S. (1998). Psychologie dynamique et psychanalyse. Paris: Masson

Cabra, M. (2005, Junho). Indefension aprendida em situación de guerra y violência extrema. Trabalho apresentado no $V$ Congresso Internacional de Trauma Psíquico y Stress Traumático, Buenos Aires, Argentina.

Cremasco, M. V. F. (2008). Violência e resiliência: Enfrentamento do traumático na clínica psicanalítica. Latin American Journal of Fundamental Psychopathology Online, 5, 222-240.

Devereux G. (1972). Ethnopsychanalyse complémentariste. Paris: Flamarion.

Ferenczi, S. (1982). Réflexions sur le traumatisme. Em M. Balint \& J. Dupont (Orgs.), Psychanalyse IV Oeuvres Complètes, Tome IV: 1927-1933 (L'équipe de traduction du Coq Héron, Trad.) (pp. 139-147). Paris: Payot. (Original publicado em 1932)

Freud, S. (1973) Esquisse pour une psychologie scientifique. Em Freud, S., La Naissance de la psychanalyse (pp. 307-396) (L'équipe de traduction de la Bibliothèque de Psychanalyse, Trad.). Paris: Presses Universitaires de France. (Original publicado em 1895)
Freud, S. (1981a). Au-delà du principe de plaisir. Em S. Freud, Essais de psychanalyse (J. Laplanche, Trad.) (pp. 41-117). Paris: Payot. (Original publicado em 1920)

Freud, S. (1981b). Psychologie des foules et analyse du moi. Em S. Freud, Essais de psychanalyse (A. Bourguignon, Trad.) (pp. 117-217). Paris: Payot. (Original publicado em 1921)

Freud, S. (1987). Notes sur le 'bloc-notes magique'. Em Freud, S., Résultats, idées, problèmes: Tome II (pp. 119-124) (L'équipe de traduction de la Bibliothèque de Psychanalyse, Trad.) Paris: Presses Universitaires de France. (Original publicado em 1924)

Giust-Desprairies, F. (2005). A identidade como processo: Entre ligação e desprendimento (J. Zugueib Neto, Trad.). Em J. Zugueib Neto (Org.), Identidades e crises sociais na contemporaneidade (pp.199-213). Curitiba: Editora da UFPR.

Hanus, M. (2006). Freud et Promáthée, un abord psychanalytique de la résilience. Em B. Cyrulnik \& P. Duval (Orgs.), Psychanalyse et résilience (pp. 187-204). Paris: Odile Jacob.

Kaës, R. \& Faimberg, H. (2003). Transmission de la vie psychique entre générations. Paris: Dunod.

Houzel, D. (2006). Psychanalyse et résilience. Em B. Cyrulnik \& P. Duval (Orgs.), Psychanalyse et résilience (pp. 247-262). Paris: Odile Jacob.

Laplanche, J. (1993). La sexualité humaine, biologisme et biologie. Paris: Presses Unviersitaires de France.

Tisseron, S. (2007). La résilience. Paris: Presses Universitaires de France. Wolf-Fédida, M. (2008). Psychopathologie fondamentale. Paris: MJWF Édition.

Zugueib Neto, J. (Org.) (2005). Identidades e crises sociais na contemporaneidade. Curitiba: Editora da UFPR.

\section{Nota:}

1 Estamos falando de intervenção psicanalítica enquanto houver a fala do afetado. Em quadros mais graves, como quadros de depressão catatônica, evidentemente há que se recorrer aos psicofármacos para mais tarde ou concomitantemente trabalhar sua elaboração simbólica e reinserção social.

\section{Sobre os autores:}

Jamil Zugueib Neto - Psicólogo, Doutor em Psicologia Social (Toulouse Le Mirail, França), pós-doutorando em Teoria Psicanalítica do Instituto de psicologia da UFRJ. Professor do Departamento de Psicologia da Universidade Federal do Paraná. Coordenador do Núcleo de Estudos dos Processos Identitários, das Etnias, das Crises e da Cultura Árabe.

Maria Virginia Filomena Cremasco - Psicóloga, Doutora em Saúde Mental (Universidade Estadual de Campinas), pós-doutorado em Psicopatologia e Psicanálise (Université Paris VII). Professora do Departamento de Psicologia da Universidade Federal do Paraná. Membro da Associação Universitária de Pesquisa em Psicopatologia Fundamental.

Endereço eletrônico: jzugueib@ufpr.br; mavicremasco@hotmail.com 